\title{
Long-Term Studies of Hemoglobin-Oxygen Affinity in Hypoxemic Dogs with a Right-to-Left Cardiac Shunt ${ }^{1}$
}

\author{
S. Bert Litwin, M.D., ${ }^{* 2}$ Amnon Rosenthal, M.D. $\dagger$ William F. Skogen, ${ }^{*}$ \\ AND MYRON B. LAVER, M.D. $\ddagger$ \\ *The Department of Cardiothoracic Surgery and The Division of Surgery of the Medical College of Wisconsin, \\ The Milwaukee Children's Hospital, Milwaukee, Wisconsin 53233; †The Department of Pediatrics of the \\ University of Michigan School of Medicine and The Department of Cardiology, The Children's IIospital, \\ Ann Arbor, Michigan 48104; and $\ddagger$ The Anesthesia Laboratories of the Harvard Medical School, The \\ Massachusetts General Hospital, Boston, Massachusetts 02114
}

Submitted for publication March 12, 1979

\begin{abstract}
Long-standing hypoxemia was surgically created in dogs by inserting an aortic homograft between the inferior vena cava and right atrium. Ligation of the caval-atrial junction resulted in a right-toleft cardiac shunt. Arterial $p \mathrm{O}_{2}$ fell immediately and $P_{50}$ increased within $20 \mathrm{~min}$. The 2,3-diphosphoglycerate concentration rose in $4 \mathrm{hr}$ following surgery, while hemoglobin concentration increased within 7 days. Alterations in hemoglobin-oxygen affinity can occur rapidly and may be beneficial compensatory responses to acute and chronic hypoxemia caused by a right-to-left cardiac shunt.
\end{abstract}

\section{INTRODUCTION}

Chronic hypoxemia secondary to cyanotic congenital heart disease is associated with a decreased hemoglobin-oxygen affinity [14]. Acute hypoxemia in human subjects taken to high altitude is also associated with a decrease in hemoglobin-oxygen aftinity [9]. These properties suggest that facilitation of $\mathrm{O}_{2}$ delivery is due to enhanced release of oxygen from the red blood cell [14].

We have described previously an animal model with hypoxemia similar to that found in patients with cyanotic heart disease [10]. This has allowed us to study immediate and long-term compensatory responses to and sequelae of blood oxygen deficiency. We wish to now report acute and chronic alterations in oxygen transport including changes in hemoglobin-oxygen affinity which occur in dogs with hypoxemia due to a substantial right-to-left cardiac shunt.

' Supported in part by U.S.P.H.S. Grant G.M. 19504-07.

${ }^{2}$ To whom reprint requests should be sent: The Milwaukee Children's Hospital, 1700 West Wisconsin Avenue, Milwaukee, Wisc. 53233.

\section{METHODS}

Fourteen dogs (14-24 kg) were made hypoxemic by surgically interposing an aortic homograft between the inferior vena cava and left atrium [10]. The inferior vena caval-right atrial junction was ligated and this resulted in a substantial right-to-left cardiac shunt. Blood samples were taken prior to and at regular intervals after surgery. Hemoglobin $(\mathrm{Hb})$ concentration, arterial $p \mathrm{O}_{2}, p \mathrm{CO}_{2}$, and $\mathrm{pH}$ measurements were performed using standard laboratory procedures.

Oxyhemoglobin dissociation curves of whole blood were performed by the method of Duvelleroy et al. [6], and expressed as $P_{50}$ (the partial pressure of oxygen at $50 \%$ saturation) corrected to a $\mathrm{pH}$ of 7.4 .

2,3-Diphosphoglycerate (2,3-DPG) concentrations were determined enzymatically using Sigma kits 35 UV (Sigma Chemical Co., St. Louis, Mo.). In five animals blood total phosphate was measured and in two animals lactate concentrations were determined using an enzymatic determination by Sigma. 
Control animals. Four dogs underwent a sham operation including all aspects of the procedure except insertion of the graft and ligation of the inferior vena cava. Blood samples were taken and procedures were performed as described for the hypoxemic animals.

Statistical evaluation of data was performed using Student's $t$ test. Values are means \pm standard deviation.

\section{RESULTS}

\section{Oxyhemoglobin Dissociation}

All animals had normal $P_{50}$ values of 27.1 $\pm 0.7 \mathrm{~mm} \mathrm{Hg}$ before the onset of hypoxemia. The $P_{50}$ increased as soon as $20 \mathrm{~min}$ after surgical completion of the shunt and continued to increase reaching a value of 31.7 $\pm 1.8 \mathrm{~mm} \mathrm{Hg}$ by $4 \mathrm{hr}$ postoperative (Fig. 1, Table 1). By $48 \mathrm{hr}$ postshunt a maximum $P_{50}$ of $32.8 \pm 2.8 \mathrm{~mm} \mathrm{Hg}$ was reached. It then stabilized and remained elevated during the remainder of the observation period (Figs. 1 and 2, Table 1).

\section{2,3-Diphosphoglycerate}

2,3-DPG concentration was normal $(0.93$ $\pm 0.29 \mathrm{M} / \mathrm{M} \mathrm{Hb}$ ) in all animals before surgery and remained stable for 2 to $3 \mathrm{hr}$ after completion of the shunt. Sharp in-

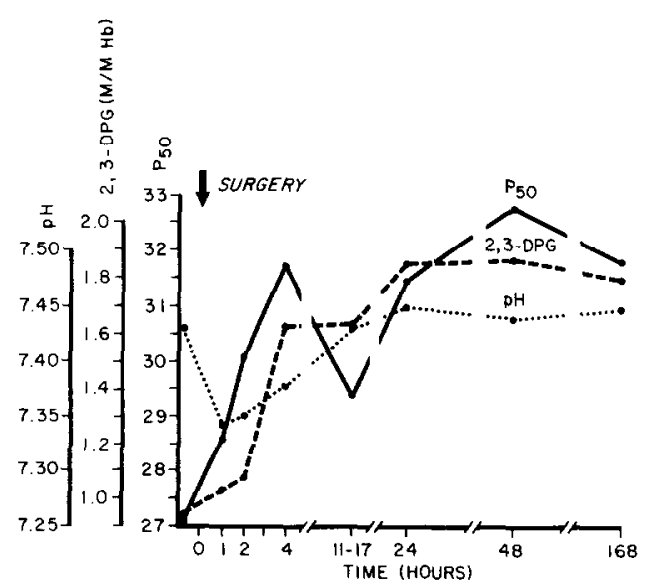

Fig. 1. Acute changes in blood $P_{50}, 2,3$-diphosphoglycerate (DPG), and arterial $\mathrm{pH}$ after surgical creation of a right-to-left cardiac shunt. creases in 2,3-DPG concentration then occurred and these increases were significant $(P<0.005)$ by $4 \mathrm{hr}$ postoperatively (Fig. 1, Tablc 1). Concentrations increased further and a maximum of $1.87 \pm 0.33 \mathrm{M} / \mathrm{M}$ $\mathrm{Hb}$ was reached $48 \mathrm{hr}$ after the onset of hypoxemia. 2,3-DPG concentration then decreased slowly during the following 9 to 12 months to $1.53 \pm 0.13 \mathrm{M} / \mathrm{M} \mathrm{Hb}$ and rcmained at this level (Figs. 1 and 2, Table 1) during the remainder of the observation period.

\section{Arterial Blood Gases}

Arterial $p \mathrm{O}_{2}$ decreased as soon as the surgical shunt was completed, and the hypoxemia persisted throughout the period of the study (Fig. 3, Table 1), $p \mathrm{O}_{2}$ rose slightly in the late follow-up period (Table 1). Whole blood $\mathrm{pH}$ decreased immediately after the onset of hypoxemia $(P<0.3)$ (Fig. 3, Table 1), returned to normal by 11-17 hr and remained constant for the remainder of the experiment (Table 1). The $p \mathrm{CO}_{2}$ rose slightly after surgery but returned to normal after 4-hr and remained at this level throughout the experiment.

\section{Phosphate and Lactate}

Total phosphate increased in five animals studied within $24 \mathrm{hr}$ after the onset of hypoxemia (Table 2). This increase was significant $(P<0.02)$ at 7 days postshunt and remained so during the next 4 weeks when measurements were taken (Table 1 ).

Serum lactate concentration did not change in two animals studied during the first 3 weeks of hypoxemia.

\section{Hemoglobin}

Hemoglobin concentration increased within 7 days postoperative and continued to rise during the ensuing 2 months (Fig. 2, Table 1). It stabilized at $18.0 \pm 1.0 \mathrm{~g} / 100 \mathrm{ml}$ $(P<0.02)$ within 2 to 3 months after surgery and remained elevated during the remainder of the experiment. 
TABLE 1

Blood Values in 14 Shunted Dogs, $\mathrm{FiO}_{2}=21 \%$

\begin{tabular}{|c|c|c|c|c|c|c|c|c|}
\hline & \multirow[b]{2}{*}{ Presurgery } & \multicolumn{7}{|c|}{ Postsurgery (hr) } \\
\hline & & 1 & $2^{a}$ & $4^{a}$ & $11-17^{a}$ & $24^{b}$ & $48^{b}$ & $168^{b}$ \\
\hline \multirow[t]{3}{*}{$\begin{array}{l}P_{\mathrm{so}} 7.4(\mathrm{~mm} \mathrm{Hg}) \\
2,3-\mathrm{DPG}(M / M \mathrm{Hg}) \\
\mathrm{Hb}(\mathrm{g} \%) \\
\mathrm{pO}_{2}(\mathrm{~mm} \mathrm{Hg})^{\prime} \\
\mathrm{pCO}_{2}(\mathrm{~mm} \mathrm{Hg})^{\prime} \\
\mathrm{pH}^{\prime}\end{array}$} & $\begin{aligned} 27.1 & \pm 0.7 \\
0.93 & \pm 0.18 \\
14.0 & \pm 1.6 \\
83 & \pm 10 \\
25.0 & \pm 9.0 \\
7.43 & \pm 0.06\end{aligned}$ & $\begin{aligned} 28.6 & \pm 1.9 \\
1.03 & \pm 0.21 \\
- & \\
44 & \pm 6 \\
36.5 & \pm 9.2 \\
7.34 & \pm 0.10\end{aligned}$ & $\begin{aligned} 30.1 & \pm 0.5 \\
1.08 & \pm 0.30 \\
& - \\
47 & \pm 6 \\
28.3 & \pm 2.3 \\
7.35 & \pm 0.05\end{aligned}$ & $\begin{aligned} 31.7 & \pm 1.8 \\
1.64 & \pm 0.39 \\
& - \\
36 & \pm 3 \\
26.6 & \pm 3.6 \\
7.38 & \pm 0.06\end{aligned}$ & $\begin{aligned} 29.4 & \pm 1.1 \\
1.62 & \pm 0.23 \\
& - \\
36 & \pm 6 \\
24.2 & \pm 4.8 \\
7.43 & \pm 0.05\end{aligned}$ & $\begin{aligned} 31.4 & \pm 2.0 \\
1.86 & \pm 0.33 \\
& - \\
39 & \pm 4 \\
24.0 & \pm 6.4 \\
7.45 & \pm 0.06\end{aligned}$ & $\begin{aligned} 32.8 & \pm 2.8 \\
1.87 & \pm 0.33 \\
& - \\
40 & \pm 5 \\
24.3 & \pm 5.0 \\
7.44 & \pm 0.03\end{aligned}$ & $\begin{aligned} 31.8 & \pm 1.2 \\
1.79 & \pm 0.28 \\
& - \\
40 & \pm 4 \\
22 & \pm 6 \\
7.45 & \pm 0.04\end{aligned}$ \\
\hline & \multicolumn{8}{|c|}{ Postsurgery (month) } \\
\hline & \multicolumn{2}{|c|}{$1^{c}$} & \multicolumn{2}{|l|}{$2^{d}$} & $3^{d}$ & \multicolumn{2}{|c|}{$12^{d}$} & $48^{e}$ \\
\hline $\begin{array}{l}P_{\mathrm{so}} 7.4(\mathrm{~mm} \mathrm{Hg}) \\
2,3-\mathrm{DPG}(M / M \mathrm{Hb}) \\
\mathrm{Hb}(\mathrm{g} \%) \\
p \mathrm{O}_{2}(\mathrm{~mm} \mathrm{Hg})^{f} \\
\mathrm{pCO}_{2}(\mathrm{~mm} \mathrm{Hg})^{f} \\
\mathrm{pH}^{f}\end{array}$ & $\begin{array}{r}32.3 \\
1.75 \\
16.5 \\
38 \\
23 \\
7.46\end{array}$ & $\begin{array}{l} \pm 2.0 \\
\pm 0.02 \\
\pm 2.2 \\
\pm 8 \\
\pm 3 \\
\pm 0.06\end{array}$ & $\begin{aligned} 32.0 & \pm 1.0 \\
1.69 & \pm 0.27 \\
18.0 & \pm 2.1 \\
37 & \pm 4 \\
27 & \pm 6 \\
7.46 & \pm 0.07\end{aligned}$ & & $\begin{aligned} 31.2 & \pm 0.9 \\
1.61 & \pm 0.29 \\
18.0 & \pm 1.0 \\
47 & \pm 7 \\
27 & \pm 2 \\
7.48 & \pm 0.03\end{aligned}$ & $\begin{aligned} 32.0 & \pm \\
1.53 & \pm \\
18.4 & \pm \\
43 & \pm \\
27 & \pm \\
7.47 & \pm\end{aligned}$ & $\begin{array}{l}1.9 \\
0.13 \\
0.9 \\
5 \\
8 \\
0.08\end{array}$ & $\begin{aligned} 31.6 & \pm 0.7 \\
1.53 & \pm 0.24 \\
18.2 & \pm 1.4 \\
48 & \pm 6 \\
27 & \pm 7 \\
7.47 & \pm 0.06\end{aligned}$ \\
\hline $\begin{array}{l}\text { a } 14 \text { dogs. } \\
\text { \& dogs. } \\
\text { e } 13 \text { dogs. } \\
\text { a } 10 \text { dogs. } \\
\text { ' } 3 \text { dogs. } \\
\text { Arterial blood. }\end{array}$ & & & & & & & & \\
\hline
\end{tabular}

\section{Control Animals}

The control animals were followed for 4 weeks after the surgical procedure. There was no significant change in the parameters studied (Table 3).

\section{DISCUSSION}

In the present study we have observed several compensatory responses to surgically induced hypoxemia. These timerelated changes are directed toward increased oxygen-carrying capacity of blood and may be classified as rapid, intermediate, or long term [5].

In our experiments, rapid compensatory responses included a decrease in blood $\mathrm{pH}$ with the onset of hypoxemia. Concomitant with this decreased $\mathrm{pH}$ was an increase in $\boldsymbol{P}_{50}$ occurring as soon as $20 \mathrm{~min}$ after the onset of right-to-left cardiac shunting. The physiological role of intracellular erythrocyte $\mathrm{pH}$ in altering hemoglobin-oxygen affinity has long been recognized (Bohr effect). Although intraerythrocyte $\mathrm{pH}$ was not recorded in our animals, a linear rela- tionship does exist between intra- and extraerythrocyte $\mathrm{pH}$ as long as organic phosphate concentration remains normal [8]. A decrease of $0.10 \mathrm{pH}$ unit accounts for an increase in $P_{50}$ of $2.5 \mathrm{~mm} \mathrm{Hg}$ [15]. Thus, the decrease in $\mathrm{pH}$ of 0.09 unit observed in our dogs in the first hour postshunt was sufficient to account for the increased $P_{50}$ of $1.5 \mathrm{~mm} \mathrm{Hg}$. With the increase in $P_{50}$,

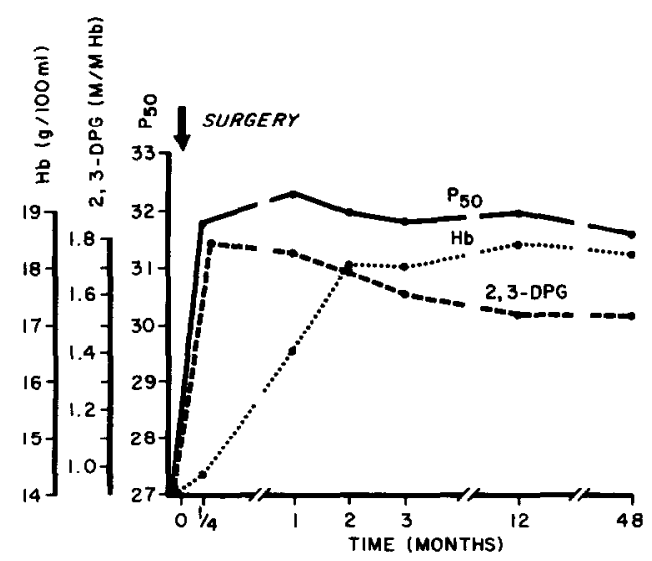

FIG. 2. Chronic changes in blood $\boldsymbol{P}_{50}, 2,3$-diphosphoglycerate (DPG), and hemoglobin (Hb) after surgical creation of a right-to-left cardiac shunt. 


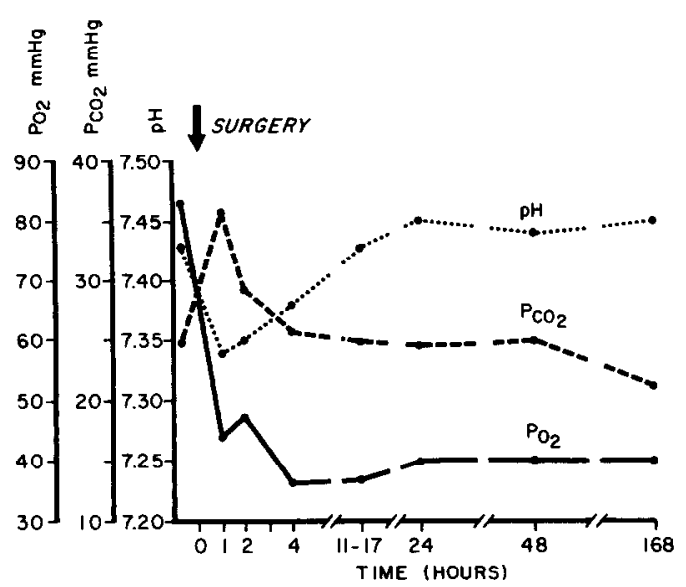

FIG. 3. Changes in arterial $p \mathrm{O}_{2}, p \mathrm{CO}_{2}$, and $\mathrm{pH}$ after surgical creation of a right-to-left cardiac shunt.

oxygen is theoretically released more readily by the red blood cell (RBC) at a tissue level.

A small but significant $(P<0.01)$ increase in $p \mathrm{CO}_{2}$ also occurred during this time period. An increased $\mathrm{CO}_{2}$ can result in an increased $\boldsymbol{P}_{50}$, independent of $\mathrm{pH}$, by binding to the $\mathrm{N}$-terminal amino acids of the hemoglobin molecule [7].

The changes in $\mathrm{pH}$ and $p \mathrm{CO}_{2}$ which we observed may be due to right-to-left cardiac shunting which was established acutely prior to a compensatory change in respiratory function. In these animals, the respiratory center may have been depressed by persistent effects of general anesthesia.

The intermediate responses to hypoxemia in our dogs include alterations in erythro- cyte metabolism resulting in increased concentrations of 2,3-DPG. 2,3-DPG is the primary organic phosphate in the erythrocyte and has been shown to increase $P_{50}$ by binding directly to the hemoglobin molecule [2, 4]. 2,3-DPG synthesis is $\mathrm{pH}$ dependent. A decreased intracellular $\mathrm{pH}$ decreases 2,3-DPG synthesis by reducing DPG mutase activity while increasing 2,3DPG degradation by virtue of increased 2,3-DPG phosphatase activity [13].

The acidosis encountered in our experiments throretically improved oxygen release by $\mathrm{RBC}$ for the first several hours while preventing increased 2,3-DPG synthesis. As soon as the $\mathrm{pH}$ returned to normal, 2,3-DPG synthesis increased, and this probably accounted for the continued elevation of the $P_{50}$ (Fig. 2). 2,3-DPG synthesis remained stimulated and concentrations reached peak values $24-48 \mathrm{hr}$ postoperative (Table 1). This elevated 2,3-DPG concentration remained throughout the experimental period although it later decreased slowly with a concomitant rise in hemoglobin concentration (Fig. 3). Concomitant with the increase in 2,3-DPG concentration, total whole blood phosphate levels increased $29 \%$ by 1 week postoperative. Phosphate levels remained elevated during the 4-week time period during which samples were taken. Serum lactate levels measured in two animals remained constant and at normal levels throughout the period of intermediate response to hypoxemia. This

TABLE 2

Blood Phosphate and Lactate Concentrations in Shunted Dogs

\begin{tabular}{|c|c|c|c|c|c|c|}
\hline & \multirow[b]{2}{*}{ Presurgery } & \multicolumn{5}{|c|}{ Post surgery } \\
\hline & & 1 day & 1 week & 2 weeks & 3 weeks & 4 weeks \\
\hline $\begin{array}{l}\text { Total blood } \\
\text { phosphate }(\mathrm{mg} \%)^{a}\end{array}$ & $3.2 \pm 0.5$ & $3.9 \pm 1.1$ & $4.5 \pm 0.4$ & $4.4 \pm 0.4$ & $4.6 \pm 0.2$ & $4.4 \pm 0.2$ \\
\hline $\begin{array}{l}\text { Lactate }(\mathrm{m} M) \\
\operatorname{dog} \text { No. } 1 \\
\operatorname{dog} \text { No. } 2\end{array}$ & $\begin{array}{l}1.54 \\
1.40\end{array}$ & - & $\begin{array}{l}1.82 \\
1.43\end{array}$ & $\begin{array}{l}1.47 \\
1.42\end{array}$ & $\begin{array}{l}1.48 \\
1.36\end{array}$ & - \\
\hline
\end{tabular}

a 5 dogs. 
TABLE 3

Blood Values in Four Sham Dogs, $\mathrm{FiO}_{2}=21 \%$

\begin{tabular}{lccccc}
\hline & \multicolumn{4}{c}{ Postsurgery } \\
\cline { 3 - 6 } & Presurgery & $1-4 \mathrm{hr}$ & $24 \mathrm{hr}$ & 2 weeks & 4 weeks \\
\hline$P_{50}(\mathrm{~mm} \mathrm{Hg})$ & $27.1 \pm 0.9$ & $26.4 \pm 2.1$ & $26.7 \pm 1.8$ & $26.4 \pm 1.8$ & $26.7 \pm 0.5$ \\
$2,3-\mathrm{DPG}(M / M \mathrm{Hb})$ & $1.20 \pm 0.06$ & $1.23 \pm 0.08$ & $1.10 \pm 0.16$ & $1.14 \pm 0.19$ & $1.14 \pm 0.25$ \\
$\mathrm{Hb}(\mathrm{g} / 100 \mathrm{ml})$ & $12.8 \pm 1.4$ & $12.8 \pm 1.4$ & $12.9 \pm 1.8$ & $13.1 \pm 1.4$ & $13.1 \pm 2.0$ \\
$p \mathrm{O}_{2}(\mathrm{~mm} \mathrm{Hg})^{a}$ & $87 \pm 8$ & $82 \pm 12$ & $89 \pm 8$ & $82 \pm 12$ & $86 \pm 11$ \\
$p \mathrm{CO}_{2}(\mathrm{~mm} \mathrm{Hg})^{a}$ & $26 \pm 2$ & $28 \pm 8$ & $26 \pm 3$ & $25 \pm 2$ & $27 \pm 3$ \\
$\mathrm{pH}^{a}$ & $7.41 \pm 0.02$ & $7.39 \pm 0.02$ & $7.40 \pm 0.03$ & $7.42 \pm 0.01$ & $7.43 \pm 0.02$ \\
\hline
\end{tabular}

${ }^{a}$ Arterial blood.

suggests no alteration in the animals' overall net metabolism.

Long-term adaptive responses to hypoxemia are largely hemopoietic with an increase in red blood cell mass [10]. Hb concentration in our animals was increased maximally at 2 to 3 months after surgery, and it remained stable and elevated after this. The etiology of this erythropoietic stimulation is clearly established, and the mechanism of its action involves increased erythropoietin production. When oxygen delivery is decreased to the renal cortical regulating center, erythropoietin production is stimulated. Erythropoietin acts directly on the bone marrow to stimulate RBC production [1]. With a significant rise in RBC mass and persistent elevation of $P_{50}$, oxygen delivery improves to the renal regulating center at a tissue level and erythropoietin production is reduced.

Other long-term adaptive responses to hypoxemia include an increase in capillary [3] and mitochondrial density [12]. Although the present study does not define these, studies are in progress to investigate these changes in dogs with a right-to-left cardiac shunt.

We have defined the morphology of the compensatory changes in oxygen transport when dogs are made hypoxemic with a right-to-left cardiac shunt. An understanding of these responses may allow manipulation of oxygen transport in order to enhance these compensatory mechanisms.

\section{REFERENCES}

1. Adamson, J. W., and Finch, C. A. Hemoglobin function, oxygen affinity, and erythropoietin. Annu. Rev. Physiol. 37: 351, 1975.

2. Benesch, R., and Benesch, R. E. The effect of organic phosphate from the human erythrocyte on the allosteric properties of hemoglobin. Biochem. Biophys. Res. Commun. 26: 162, 1967.

3. Cassin, S., Gilbert, R. D., and Johnson, E. M. "Capillary Development during Exposure to Chronic Hypoxia." United States Air Force School of Aerospace Medicine, S.A.M.-TR-66-16, 1966.

4. Chanutin, A., and Curnish, R. R. Effect of organic and inorganic phosphates on the oxygen equilibrium of human crythrocytes. Arch. Biochem. Biophys. 121: 96, 1967.

5. DeVerdier, C. H., and Garby, L. 2,3-Diphosphoglycerate and respiratory function of hemoglobin. Biochimie 54: 613, 1972.

6. Duvelleroy, M. A., Buckles, R. G., Rosenkaimer, S., Tung, C., and Laver, M. B. An oxyhemoglobin dissociation analyzer. J. Appl. Physiol. 28, 227, 1970.

7. Kilmartin, J. V., and Rossi-Bernardi, L. Inhibition of $\mathrm{CO}_{2}$ combination and reduction of the Bohr effect in haemoglobin chemically modified at its amino groups. Nature (London) 222: 1243, 1969.

8. Lenfant, C., and Sullivan, K. Adaption to high altitude. N. Engl. J. Med. 284: 1298, 1971.

9. Lenfant, C., Torrance, J., English, E., Finch, C. A., Reynafarje, C., Ramos, J., and Faura, J. Effect of altitude on oxygen binding by hemoglobin and on organic phosphate levels. J. Clin. Investig. 47: 2652, 1968.

10. Litwin, S. B., Rosenthal, A., Skogen, W. F., Wright, K. A., Friedberg, D. Z., Youker, J. E., and Laver, M. B. An animal model for the study of chronic hypoxemia including long-term followup results. J. Surg. Res. 24: 107, 1978.

11. Petschow, D., Wurdinger, I., Baumann, R., Duhin, J., Braunitzer, G., and Bauer, C. Causes 
of high blood $\mathrm{O}_{2}$ affinity of animals living at high altitude. J. Appl. Physiol. 42: 139, 1977.

12. Reynafarje, B. Myoglobin content and enzymatic activity of muscle and altitude adaption. J. Appl. Physiol. 17: 301, 1962.

13. Rorth, M. Hemoglobin interactions and red cell metabolism. Ser. Haematol. 5: 59, 1972.

14. Rosenthal, A., Mentzer, W. C., Eisenstein, E. B.,
Natham, D. G., Nelson, N. M., and Nadas, A. S. The role of red blood cell organic phosphate in adaption to congenital heart disease. Pediatrics 47: 537,1971

15. Shappell, S. D., and Lenfant, C. J. Adaptive genetic and iatrogenetic alterations of the oxyhemoglobin-dissociation curve. Anesthesiology 37: $127,1972$. 